\title{
Incidence of Subcaudal Melanophores in Pre-extrusion Larvae of Redfish Species in the Newfoundland-Labrador Area
}

\author{
Wilfred Templeman \\ J. L. Paton Chair of Marine Biology and Fisheries \\ Memorial University of Newfoundland \\ St. John's, Newfoundland, Canada
}

\begin{abstract}
Pre-extrusion larvae of female redfish from the Newfoundland-Labrador area in 1958-66 were examined for the presence or absence of subcaudal melanophores. The larval samples from the sharp-beaked mentella-type redfish were readily separated into two groups, one with all or nearly all of the larvae possessing subcaudal melanophores and recognized as Sebastes fasciatus, and the other tending to have a small fraction or none of the larvae with these melanophores and recognized as Sebastes mentella. Moreover, the larvae of $S$. fasciatus had on the average a greater number of subcaudal melanophores which were also usually larger than those of $S$. mentella. However, the presence of these melanophores in many of the North American S. mentella contrasts with the reported absence of subcaudal melanophores in larvae of Icelandic and Northeast Atlantic and of the North Atlantic oceanic populations of $S$. mentella. The female parents of larvae assigned to $S$. fasciatus had significantly lower vertebral, anal fin-ray and dorsal fin-ray numbers than those of larvae assigned to $S$. mentella.
\end{abstract}

The occurrence of subcaudal melanophores in Sebastes marinus larvae generally resembled that in the North American $S$. mentella (as distinct from $S$. fasciatus) except that the former tended to have more larvae with melanophores than the latter. The meristic characteristics of the $S$. marinus parents more closely resembled those of $S$. mentella than those of $S$. fasciatus, but the fin-ray numbers in $S$. marinus tended to be lower than in S. mentella

\begin{abstract}
In the Northwest Atlantic area from Flemish Cap to southern Labrador, the spawning females of S. mentella appear to live deeper and extrude larvae earlier in the year than those of $S$. fasciatus and S. marinus. These differences in distribution and biology and the occurrence of large immature $S$. mentella in the northern part of Newfoundland-Labrador area have management implications which are discussed
\end{abstract}

\section{Introduction}

Tåning (1949) (see also Hansen and Andersen (1961) and Tåning and Bertelsen (1961) for more detail) discovered large quantities of oceanic redfish fry in late June and early July in the area between the south of Iceland and Greenland and north of Flemish Cap. In the area north of Flemish Cap, he also found the young of American redfish which he believed were carried by currents from Flemish Cap. Tåning and Bertelsen (1961) noted the absence in the oceanic form and the presence in the American form of a melanophore in the cleft between the two large hypural plates, the latter larvae thus resembling those of Sebastes viviparus. These American larvae noted by Tåning (1949) were larger than, and the caudal melanophore pattern different from, those subsequently described by Templeman and Sandeman (1959), who found, in their examination of pre-extrusion larvae of Sebastes marinus and of the sharp-beaked mentella-type redfish from the continental slopes of the Newfoundland-Labrador area, that a much larger proportion of the mentellatype larvae had subcaudal melanophores similar to those in $S$. viviparus larvae of Tåning and Bertelsen (1961).

These observations in the Northwest Atlantic stimulated a number of researchers to examine welldeveloped but unextruded larvae of $S$. mentella from the central and eastern regions of the North Atlantic (Kotthaus, MS 1961; Henderson, 1964; Henderson and Jones, 1964; Raitt, 1964; Jones, 1968). These authors reported that the larvae of $S$. mentella did not possess the group of subcaudal melanophores noted by Templeman and Sandeman (1959). The oceanic redfish population southwest of Iceland and south and southwest of Greenland, and by inference the oceanic redfish larvae extending from these areas to north of Flemish Cap, are S. mentella (Henderson and Jones, 1964; Zakharov, 1964; Templeman, 1967).

The presence of subcaudal melanophores in larvae from sharp-beaked redfish of the 
Newfoundland-Labrador area (Templeman and Sandeman, 1959) and their absence in larvae of $S$. mentella of the Northeast Atlantic, the researches of Barsukov (1968, 1972) and Barsukov and Zakharov (1972) on body form, depth and other relationships in redfish of the North Atlantic, the differences in the location of attachment of the gasbladder muscles (Hallacher, 1974), and the studies of Litvinenko (1974) on coloration of young redfish, make it evident that there is, in the North American area of the Northwest Atlantic, a sharp-beaked mentella-type redfish different from S. mentella. Although Storer's (1856) description of Sebastes fasciatus from off the American coast was very brief. its meristics were probably those of the typical North American sharpbeaked redfish rather than those of $S$. mentella or $S$. marinus. The use of $S$. fasciatus for the American sharp-beaked redfish was noted by Tåning and Bertelsen (1961) and was introduced by Tåning in data on meristics subsequently noted by Kelly et al. (1961). The subject was also mentioned briefly by Tåning (1949) as being a name given by Storer (1856) to the American species, whose larvae were found by Tåning to possess a caudal melanophore not present in the larvae of oceanic $S$. marinus (now known as $S$. mentella). Barsukov (1968) and Barsukov and Zakharov (1972) concluded, and Templeman (1976) agreed, that $S$. fasciatus should be recognized and used where possible to distinguish this redfish which is different from $S$. mentella in its morphological and biological characteristics, in order to stimulate further research. S. fasciatus is used in this paper as a working name for this purpose. If proof of biological separation were necessary before a name can be used, very few closely-related fish species, especially those from deep water, could be separated specifically. The above subject is discussed in more detail by Templeman (1976).

Templeman and Sandeman (1957) reported two varieties of redfish from the Newfoundland area, the common sharp-beaked mentella-type and the less common marinus-type, and Templeman (1957) reported the presence of the latter in shallower water and the former in deeper water of the Flemish Cap area. Templeman (1959) reported the relative distribution of both types in the Newfoundland area, and Templeman (1961a, b) reported the proportions of these types taken during research vessel cruises in 1959 and 1960 off Baffin Island and Labrador. It was concluded that young mentella-type redfish taken in 1959 off Baffin Island had drifted from West Greenland. It is now known that female redfish at West Greenland are usually immature (Zakharov, 1962, 1967; Biester et al., MS 1962; Templeman. 1966), so that these mentellatype fry had probably drifted from Southwest Iceland or East Greenland by way of West Greenland. Alternatively, they may have been produced by the oceanic population of $S$. mentella.

Bainbridge and Cooper (1971) summarized the knowledge of larval redfish distribution from the Continuous Plankton Recorder Surveys, which was the subject of a series of papers by Henderson (1961, $1964,1965 a, 1965 b, 1968)$. The oceanic redfish larvae in the region extending from southwest of Iceland and south of Greenland to north of Flemish Cap did not have subcaudal melanophores and were thus likely to have been derived from the oceanic population of adults, previously shown to be of the sharp-beaked variety and hence $S$. mentella. Most of the redfish larvae from southern Labrador and the Northeast Newfoundland Shelf had subcaudal melanophores and thus were mainly S. fasciatus. However, because the southern Labrador area was sampled by ships whose passage was through the Strait of Belle Isle, it is probable that this area was not often or usually sampled early in the year due to ice conditions, and that most of the $S$. mentella larvae which are extruded earlier than those of $S$. fasciatus, were missed in the plankton recorder sampling of the area. The redfish larvae from Flemish Cap were almost all without subcaudal melanophores and could have been $S$. marinus or S. mentella. However, since sharp-beaked redfish are dominant on Flemish Cap (Templeman, 1976) and S. mentella are much more abundant than $S$. fasciatus (from the present data), these larvae were therefore mainly S. mentella. Most of the redfish larvae in plankton recorder samples from the Scotian Shelf and the Gulf of Maine possessed subcaudal melanophores, the proportion increasing from north to south. The parents of these larvae were therefore mainly S. fasciatus. Barsukov $(1968,1972)$ and Barsukov and Zakharov (1972) concluded that both S. mentella and $S$. fasciatus were present on the North American Shelf, the former more common toward the north in deeper water and the latter more common toward the south in shallower water. Templeman (1973), from the distribution of redfish parasites, concluded that the oceanic $S$. mentella must intermingle with the continental slope populations of North American redfish.

The present investigation was directed especially toward evidence of differences between the larvae of the two varieties of the sharp-beaked mentella-type redfish, and incidentally of $S$. marinus, from a study of subcaudal melanophores in unextruded larvae of females from parts of the Newfoundland area.

\section{Materials and Methods}

The materials for this paper were collected during some bottom trawl surveys conducted by research vessels of the St. John's Biological Station in 1958-66. 


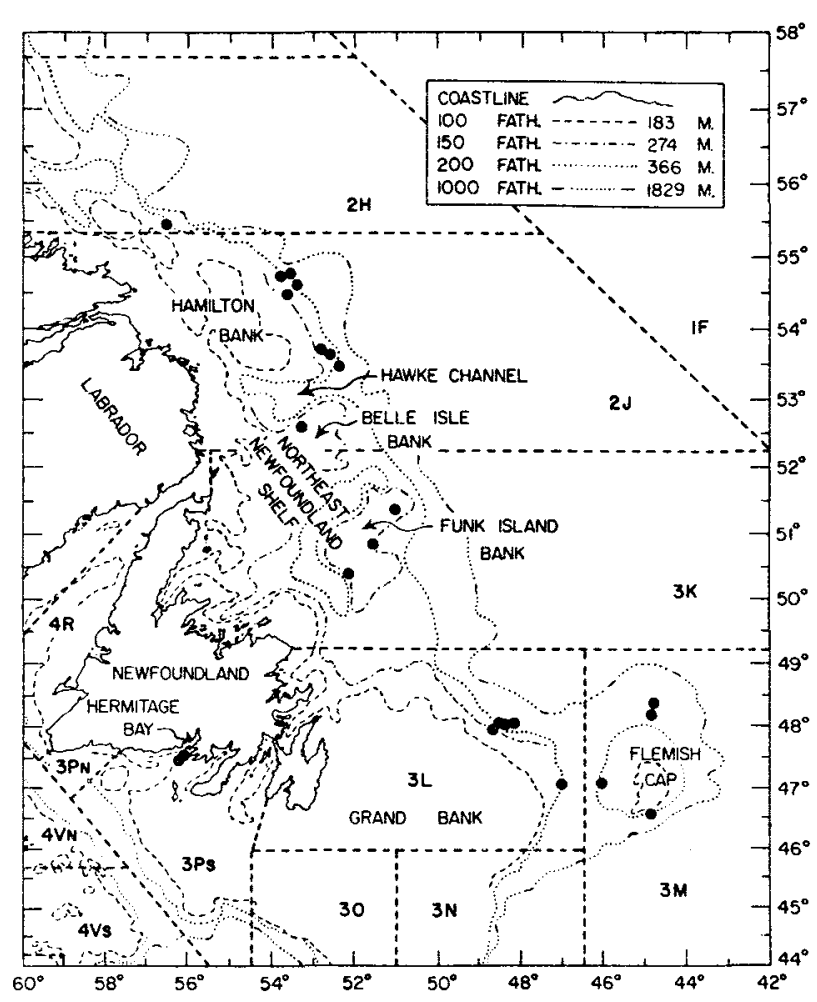

Fig. 1. Map of Newfoundland-Labrador area showing locations of capture of female redfish from which the samples of preextrusion larvae were obtained.

Soon after capture, unextruded redfish larvae, with some hatched and as close as possible to extrusion, were obtained in good condition from parent females (from locations noted in Fig. 1 and Table 1), identified individually as $S$. marinus or the sharp-beaked mentella-type, and preserved in $5 \%$ formalin. For some of the female parents, the vertebral number and the dorsal and anal fin-ray numbers were counted and checked under the author's supervision. The urostylar half-vertebra was included as a vertebra. The posterior 2 dorsal and 2 anal fin-rays with bases located close together and related to a single neural or haemal pterygiophore were counted as one. Counts of skeletons with fused vertebrae were not used in this study.

The presence or absence of subcaudal melanophores in the larvae were observed through a binocular dissecting microscope at a magnification of $20 \mathrm{X}$, but additionally at higher magnifications when unusually small melanophores were present. A subsample of 20 larvae taken at random from the container in which the sample was preserved was examined for melanophores. Information on redfish larvae examined by Templeman and Sandeman (1959) from collections in 1958 was utilized by taking the results of observations on the last 20 of the 120 larvae initially examined from each parent. Comparison of sample frequencies of larvae with subcaudal melanophores from 44 mentella-type female parents (table 3 of Templeman and Sandeman, 1959), when 120 larvae per sample were used, with those from the same parents (1958 data in Table 1 of this paper), when the last 20 larvae examined were used (and similarly for 37 S. marinus specimens of the 1958 data), indicated that the frequency spread was not seriously changed by using the smaller sample size.

The data obtained on subcaudal melanophores in larvae of the sharp-beaked mentella-type were used to nominally identify $S$. fasciatus and $S$. mentella. Meristic characteristics of the female parents, thus identified, were used, in relation to the stage of egg and larval development in other mature females of mentella-type redfish whose larvae were not examined for melanophores, to estimate the relative numbers of $S$. fasciatus and $S$. mentella at different depths and stages of egg development, hatching and larval extrusion, and thus obtain information on the approximate spawning times in these species. Redfish lengths mentioned in this paper are fork lengths from chin with mouth closed to mid-fork of the caudal fin.

\section{Results}

\section{Subcaudal melanophores and redfish species}

Data on the incidence of subcaudal melanophores in the larvae of sharp-beaked mentella-type and $S$. marinus females in various parts of the NewfoundlandLabrador area are listed in Table 1.

Mentella-type redfish. The frequency of occurrence of subcaudal melanophores in samples of 20 larvae from each female parent indicates two fairly distinct groups of redfish (Table 1). One group usually had all 20 larvae, and occasionally 19-13 larvae in samples of 20 , with melanophores. These larvae usually had 1-3 and occasionally 4 or 5 subcaudal melanophores which when expanded were quite large with much black pigment. In the other group of mentella-type redfish, the subcaudal melanophores were either absent, or present only in very small numbers of larvae, the frequency of occurrence being usually $0-4$ and occasionally up to 8 larvae in samples of 20 larvae per female parent. (The two redfish each with subcaudal melanophores in 11 larvae of 20 examined are dealt with below.) In the second group of redfish, the larvae with subcaudal melanophores had typically 1 and occasionally 2 very small melanophores, some of which were so tiny when contracted that they were barely visible under $20 \times$ magnification. Examination under higher magnification indicated that they had typical black 
TABLE 1. Numbers of female redfish in which 0-20 larvae possessed subcaudal melanophores in a sample of 20 larvae per female parent from the NewfoundlandLabrador area.

\begin{tabular}{|c|c|c|c|c|c|c|c|c|c|c|c|c|c|c|c|c|c|c|c|c|c|c|c|c|c|c|c|}
\hline \multirow[b]{2}{*}{ Div. } & \multirow[b]{2}{*}{ Dates } & \multicolumn{2}{|c|}{ Position } & \multirow{2}{*}{$\begin{array}{c}\text { Fishing } \\
\text { depth } \\
(\mathrm{m})\end{array}$} & \multirow{2}{*}{$\begin{array}{c}\text { Bottom } \\
\text { temp. } \\
\left({ }^{\circ} \mathrm{C}\right)\end{array}$} & \multirow{2}{*}{$\begin{array}{l}\text { No. of } \\
\text { female } \\
\text { parents }\end{array}$} & \multicolumn{21}{|c|}{$\begin{array}{l}\text { Number of female redfish in which 0-20 larvae possessed subcaudal melanophores in a } \\
\text { sample of } 20 \text { larvae examined per female parent }\end{array}$} \\
\hline & & Lat $N$ & Long W & & & & 0 & 1 & 2 & 3 & 4 & 5 & 6 & 7 & 8 & 9 & 10 & 11 & 12 & 13 & 14 & 15 & 16 & 17 & 18 & 19 & 20 \\
\hline \multicolumn{28}{|c|}{ Mentella-type (Sebastes mentella and S. fasclatus) } \\
\hline \multirow[t]{2}{*}{$2 \mathrm{H}$} & $4 \mathrm{Aug} / 60$ & $55^{\circ} 28^{\prime}$ & $56^{\circ} 35^{\prime}$ & $318-329$ & 1.04 & 2 & - & - & - & - & - & -- & - & - & - & & - & - & - & - & - & - & - & - & - & - & 2 \\
\hline & & $55^{\circ} 27^{\prime}$ & $56^{\circ} 36^{\prime}$ & $360-375$ & 1.45 & 2 & - & - & - & - - & - & -- & -- & -- & - & - & - & - & - & - & - & - & - & - & - & - & 2 \\
\hline \multirow[t]{8}{*}{$2 J$} & $16 \mathrm{May} / 64$ & $52^{\circ} 37^{\prime}$ & $53^{\circ} 17^{\prime}$ & $187-238$ & 1.80 & 9 & - & - & - & - & - & - & - & - & - & - & - & - & - & - & - & - & 1 & - & - & 2 & 6 \\
\hline & 8 Jun/58 & $54^{\circ} 30^{\prime}$ & $53^{\circ} 38^{\prime}$ & 276 & 2.15 & 1 & - & - & - & - & - & -1 & - & - & - & - & - & - & - & - & - & - & - & - & - & - & 1 \\
\hline & $6 \mathrm{Aug} / 60$ & $54^{\circ} 45^{\prime}$ & $53^{\circ} 50^{\prime}$ & 320 & 4.00 & 1 & - & - & - & - & - & - & -- & -1 & -- & - & - & - & - & - & - & - & - & - & - & - & 1 \\
\hline & 9 Aug $/ 60$ & $53^{\circ} 43^{\prime}$ & $52^{\circ} 51^{\prime}$ & $320-326$ & 4.12 & 1 & - & - & - & - & - & -- & - & - & - & - & - & - & - & - & - & - & - & - & - & - & 1 \\
\hline & $11 \mathrm{Aug} / 60$ & $53^{\circ} 39^{\prime}$ & $52^{\circ} 38^{\prime}$ & $360-371$ & 4.45 & 1 & - & - & - & - - & - & - & - & $-\ldots$ & - & - & - & - & - & - & - & - & - & - & - & - & 1 \\
\hline & $16 \mathrm{Apr} / 63$ & $53^{\circ} 28^{\prime}$ & $52^{\circ} 25^{\prime}$ & 457 & 3.42 & 7 & 2 & 4 & - & 1 & - & - & - & - & - & - & - & - & - & - & - & - & - & - & - & - & - \\
\hline & $6 \mathrm{Aug} / 60$ & $54^{\circ} 47^{\prime}$ & $53^{\circ} 36^{\prime}$ & 463 & 4.34 & 1 & - & $\cdots-$ & - & - & - & -- & - & -- & -- & - & - & - & - & - & - & - & - & - & - & - & 1 \\
\hline & 10 Jun/58 & $54^{\circ} 38^{\prime}$ & $53^{\circ} 25^{\prime}$ & $457-468$ & 3.39 & 1 & - & - & - & - & -- & -- & -- & -- & - & - & - & - & - & - & - & - & - & - & -- & - & 1 \\
\hline \multirow[t]{4}{*}{$3 K$} & $17 \mathrm{Apr} / 63$ & $51^{\circ} 22^{\prime}$ & $51^{\circ} 04^{\prime}$ & 229 & 1.98 & 3 & - & - & - & - & - & - & -- & - & -- & - & - & - & - & - & - & - & - & - & - & - & 3 \\
\hline & $6 \mathrm{Apr} / 64$ & $51^{\circ} 24^{\prime}$ & $51^{\circ} 03^{\prime}$ & $218-230$ & 3.16 & 10 & - & - & - & - & - & - & - & - & - & & - & - & - & - & - & - & - & - & - & - & 10 \\
\hline & 17-19 May/64 & $50^{\circ} 52^{\prime}$ & $51^{\circ} 35^{\prime}$ & $214-232$ & 2.73 & 30 & - & - - & - & - & - & - & - & -1 & -1 & - & - & - & - & - & 1 & - & - & - & 2 & 1 & 26 \\
\hline & $17 \mathrm{Apr} / 66$ & $51^{\circ} 22^{\prime}$ & $51^{\circ} 06^{\prime}$ & $220-223$ & 3.16 & 29 & - & - & - - & - & - & -- & - & - & - & - & - & - & - & 1 & - & 2 & 1 & 1 & - & 1 & 23 \\
\hline \multirow[t]{7}{*}{$3 \mathrm{~L}$} & $28 \mathrm{Mar} / 61$ & $47^{\circ} 58^{\prime}$ & $48^{\circ} 42^{\prime}$ & $271-274$ & 2.29 & 1 & - & - & - & - & - & - & - & -- & - & - & - & - & - & - & - & - & $\rightarrow$ & - & - & - & 1 \\
\hline & $29 \mathrm{Mar} / 61$ & $48^{\circ} 02^{\prime}$ & $48^{\circ} 31^{\prime}$ & $315-320$ & 3.59 & 5 & - & - & - & - & - & $\cdots-$ & - & -1 & -- & - & - & - & - & - & - & - & - & - & - & 1 & 4 \\
\hline & $26 \mathrm{Mar} / 61$ & $47^{\circ} 05^{\prime}$ & $47^{\circ} 00^{\prime}$ & $311-355$ & 3.66 & 1 & - & - & - & - & - & - & - & - & -- & - & - & - & - & - & - & - & - & - & - & -- & 1 \\
\hline & $29 \mathrm{Mar} / 61$ & $48^{\circ} 03^{\prime}$ & $48^{\circ} 30^{\prime}$ & $364-371$ & 3.48 & 1 & - & - & - & - & -- & -- & -- & - & -- & - & - & - & - & - & - & - & - & - & - & - & 1 \\
\hline & $29 \mathrm{Mar} / 61$ & $48^{\circ} 04^{\prime}$ & $48^{\circ} 24^{\prime}$ & $433-446$ & 3.58 & 7 & - & 1 & 1 & 1 & - & - & $1-$ & -- & - & - & - & - & - & - & - & - & - & - & - & - & 3 \\
\hline & $18 \mathrm{Apr} / 63$ & $48^{\circ} 05^{\prime}$ & $48^{\circ} 30^{\circ}$ & 457 & 3.50 & 16 & - & - & 2 & - & - & - & $1-$ & -- & -- & & - & - & - & - & - & - & - & - & - & 1 & 12 \\
\hline & $29 \mathrm{Mar} / 61$ & $48^{\circ} 04^{\prime}$ & $48^{\circ} 09^{\prime}$ & $501-521$ & 3.71 & 27 & 7 & 5 & 3 & 4 & 2 & - & 1 & $1-$ & - & - & - & 1 & - & - & - & - & - & - & -- & - & 3 \\
\hline \multirow[t]{5}{*}{$3 M$} & 25-30 Jun/58 & $47^{\circ} 05^{\prime}$ & $46^{\circ} 00^{\prime}$ & $271-373$ & - & 12 & - & - & - & - & - - & - - & $\ldots$ & $\ldots$ & -- & - & - & - & - & - & - & - & - & 1 & - & - & 11 \\
\hline & $23 \mathrm{Mar} / 61$ & $46^{\circ} 34^{\prime}$ & $44^{\circ} 49^{\prime}$ & $366-439$ & 3.75 & 4 & 1 & 1 & - & - & 1 & - & $1-$ & - & - & - & - & - & - & - & - & - & - & - & - & - & - \\
\hline & $21 \mathrm{Mar} / 61$ & $48^{\circ} 13^{\prime}$ & $44^{\circ} 47^{\prime}$ & 457 & 4.22 & 8 & 3 & 2 & 1 & - & - & - & - & 1 & $1-$ & - & - & - & - & - & - & - & - & - & - & - & - \\
\hline & 21 Mar/61 & $48^{\circ} 14^{\prime}$ & $44^{\circ} 49^{\prime}$ & $521-541$ & 3.75 & 16 & 3 & 6 & 3 & 3 & 1 & -- & - & - & -- & - & - & - & - & - & - & - & - & - & - & - & - \\
\hline & $21 \mathrm{Mar} / 61$ & $48^{\circ} 22^{\prime}$ & $44^{\circ} 45^{\prime}$ & $633-640$ & 3.67 & 1 & - & - & 1 & - & - & - & - - & - & - & - & - & 一 & - & $\rightarrow$ & - & - & - & - & - & - & - \\
\hline \multirow[t]{2}{*}{$3 p$} & $3-11 \mathrm{Jul} / 58$ & $47^{\circ} 33^{\prime}$ & $56^{\circ} 05^{\prime}$ & $241-256$ & - & 30 & - & - & - & - & - & - & - - & - - & - & - & - & 1 & - & - & - & - & - & - & 1 & 3 & 25 \\
\hline & & & & & Total & 227 & 16 & 191 & 11 & 9 & 4 & - & 4 & 2 & $1-$ & - & - & 2 & - & 1 & 1 & 2 & 2 & 2 & 3 & 9 & 139 \\
\hline \multicolumn{28}{|c|}{ Sebastes marfnus } \\
\hline $2 \mathrm{~J}$ & $16 \mathrm{Apr} / 63$ & $53^{\circ} 28^{\prime}$ & $52^{\circ} 25^{\prime}$ & 457 & 3.42 & 1 & - & - & - & - & 1 & - & - & - & - & - & - & - & - & - & - & - & - & - & - & - & - \\
\hline & $10 \mathrm{Jun} / 58$ & $54^{\circ} 38^{\prime}$ & $53^{\circ} 25^{\prime}$ & $457-468$ & 3.39 & 24 & 1 & 1 & 3 & 2 & 5 & 2 & 5 & 1 & $1-$ & - & 1 & - & 2 & - & - & - & - & - & - & - & - \\
\hline $3 K$ & 19 May/64 & $50^{\circ} 23^{\prime}$ & $52^{\circ} 08^{\prime}$ & $214-221$ & 2.64 & 6 & 1 & 2 & 1 & - & 1 & - & - & - & - & - & - & - & - & 1 & - & - & - & - & - & - & - \\
\hline & $17 \mathrm{Apr} / 66$ & $51^{\circ} 22^{\prime}$ & $51^{\circ} 06^{\prime}$ & $220-223$ & 3.16 & 1 & - & - & 1 & & - & - & $-\cdots$ & -- & - & - & - & - & - & - & - & - & - & - & - & - & - \\
\hline $3 L$ & $29 \mathrm{Mar} / 61$ & $48^{\circ} 02^{\prime}$ & $43^{\circ} 31^{\prime}$ & $315-320$ & 3.59 & 2 & 1 & 1 & - & - & $\ldots$ & - & - & -1 & - & - & - & - & - & - & - & - & - & - & - & - & - \\
\hline & $29 \mathrm{Mar} / 61$ & $48^{\circ} 03^{\prime}$ & $48^{\circ} 30^{\prime}$ & $364-371$ & 3.48 & 1 & - & - & - & 1 & - & $\cdots$ & $-\cdots$ & - & - - & - & - & - & - & - & - & 一 & - & - & - & - & - \\
\hline $3 P$ & 12-17 May/58 & $47^{\circ} 28^{\circ}$ & $56^{\circ} 13^{\prime}$ & $199-232$ & - & 13 & 2 & 2 & 2 & 2 & - & 1 & 1 & 1 & $1-$ & - & - & - & 1 & - & - & - & - & - & - & - & 一 \\
\hline & & & & & Tota! & 48 & 5 & 6 & 7 & 5 & 7 & 3 & 6 & 2 & 2 & - & 1 & - & 3 & 1 & - & - & - & - & - & - & - \\
\hline
\end{tabular}

pigment in the usual position between the two subcaudal neuromasts (see Templeman and Sandeman (1959) for illustrations of these neuromasts and the relation of the melanophores to them). The melanophores of these larvae usually had less pigment and were smaller and fainter than in the first group. In this regard, the melanophores of the second group resembled those in $S$. marinus, as described and illustrated by Templeman and Sandeman (1959). The first group of mentella-type redfish with larvae possessing larger and more numerous melanophores was usually from shallower depths and taken later in the year than the second group of mentella-type redfish with larvae possessing fewer and smaller melanophores or no melanophores.

S. fasciatus and S. mentella. The 2 groups of mentella-type redfish are well separated in Table 1 , except for 2 specimens in which 11 larvae (ơ 20 in each sample) had subcaudal melanophores. The first group with melanophores in 0-8 larvae has been ascribed to Sebastes mentella Travin, 1951, and the second group with melanophores in 13-20 larvae has been ascribed to Sebastes fasciatus Storer, 1856, the agrument for doing so being continued as further data are presented.

Of the 2 mentella-type specimens with subcaudal melanophores in 11 larvae (of 20 per sample), one with $95 \%$ of larvae hatched was taken in Hermitage Bay, (Div. 3P) at 241-256 m in July 1958 and reported by Templeman and Sandeman (1959) to have melanophores in 58 of 120 larvae examined. Fifty-three larvae had 1 and 5 larvae had 2 subcaudal melanophores, or an average of 1.09 melanophores per larva with melanophores, compared with an average of 
1.88 melanophores for the remaining 43 mentella-type redfish (now ascribed to $S$. fasciatus) of Templeman and Sandeman (1959) and with an average of 1.11 for the more recent $S$. mentella samples reported in this paper. The melanophores in the larvae of this specimen were tiny and faint (resembling those of $S$. marinus) and contained a smaller amount of pigment than was usual for $S$. fasciatus. A subcaudal melanophore in a larva of this fish is illustrated by Templeman and Sandeman (1959, fig. 4A) in comparison with melanophores in larvae of other mentella-type specimens (fig. 4C, D, F) which have now been called $S$. fasciatus. This specimen was therefore presumed to be $S$. mentella.

The other mentella-type redfish with subcaudal melanophores in 11 larvae (of 20 examined) was taken on the northeast slope of Grand Bank (Div. 3L) at $501-521 \mathrm{~m}$ in March 1961, together with 3 specimens assigned to $S$. fasciatus in which subcaudal melanophores were present in all 20 larvae examined from each fish and 23 specimens assigned to $S$. mentella with melanophores in 0-8 larvae of 20 examined from each fish. In this specimen, each larva with melanophores had 1 and sometimes 2 tiny melanophores, the average being 1.3 per larva in 19 larvae ( 8 from another subsample additional to the 11 larvae examined routinely) with melanophores. This specimen was likewise presumed to be $S$. mentella.

In studies of this type where occasionally the number of larvae with subcaudal melanophores falls intermediate between those which can definitely be assigned to $S$. fasciatus on the one hand and to $S$. mentella on the other, the specimens should be omitted from the comparisons or the melanophores in more larvae examined carefully for their affinities with typical larvae of $S$. fasciatus and S. mentella before they are assigned to species. The latter procedure was followed in this paper.

S. marinus. In reafish identified as $S$. marinus (Table 1), the most common numbers of larvae with subcaudal melanophores per sample of 20 examined from each female parent were from 0 to 6 but there were as many as $12-13$ larvae in some samples. These subcaudal melanophores, when present, were, as in $S$. mentella, fewer in number and fainter with less pigment than in S. fasciatus, formerly described and illustrated by Templeman and Sandeman (1959) as North American mentella-type redfish. The depths of capture of $S$. marinus were typically shaliower than for S. mentella in areas where both species were found.

\section{Relative numbers of subcaudal melanophores in redfish larvae}

It is apparent from Table 1 that $S$. marinus had a higher proportion of larvae with subcaudal melanophores (21\%) than S. mente/la (11\%). Only $10 \%$ of the 48 samples of 20 larvae from S. marinus and $24 \%$ of the 68 samples from S. mentella had larvae with no melanophores. For $S$. fasciatus, on the other hand, all 20 larvae in $87 \%$ of the 159 samples examined possessed melanophores. In the original data of Templeman and Sandeman (1959) where 120 larvae constituted a sample from each specimen, all 120 larvae had melanophores in $67 \%$ of the 43 mentellatype redfish (now called $S$. fasciatus) examined, whereas none of the $37 \mathrm{~S}$. marinus examined had all 120 larvae without subcaudal melanophores, the greatest numbers of larvae without melanophores being 117 in one sample and 113 in another. Increasing the number of larvae per sample for $S$. mentella would similarly reduce the percentage of samples with no subcaudal melanophores in the larvae.

The maximum number of subcaudal melanophores in a larva (of 20 per sample) was greatest in S. fasciatus, being usually 3 but often 2 or 4 and occasionally 5 (Table 2). For $S$. mentella and $S$. marinus, the greatest number of melanophores was usually 1 but ranged from 0 to 2, except in S. marinus where one larva was noted with 3 melanophores. These results indicate a considerable distinction between $S$. mentella and $S$. marinus on the one hand and $S$. fasciatus on the other but no apparent difference between areas for each species.

Data for comparing the average numbers of subcaudal melanophores per larva were derived from

TABLE 2. Numbers of female redfish with maximum number of subcaudal melanophores per larva in samples of 20 larvae per female parent.

\begin{tabular}{|c|c|c|c|c|c|c|c|}
\hline \multirow[b]{2}{*}{ Species } & \multirow[b]{2}{*}{ Div. } & \multicolumn{6}{|c|}{$\begin{array}{l}\text { No. of females with maximum number } \\
\text { of melanophores }(0-5) \text { per larva }\end{array}$} \\
\hline & & 0 & 1 & 2 & 3 & 4 & 5 \\
\hline \multirow[t]{7}{*}{ S. fasciatus } & $2 \mathrm{H}$ & - & - & 2 & 2 & - & - \\
\hline & $2 J$ & - & - & 4 & 8 & 3 & - \\
\hline & $3 K$ & - & - & 10 & 45 & 13 & 3 \\
\hline & $3 \mathrm{~L}$ & - & - & 3 & 17 & 7 & - \\
\hline & $3 \mathrm{M}$ & - & - & 5 & 4 & 3 & - \\
\hline & $3 P$ & - & - & 5 & 20 & 4 & - \\
\hline & Total & - & - & 29 & 96 & 30 & 3 \\
\hline \multirow[t]{5}{*}{ S. mentella } & $2 J$ & 2 & 5 & - & - & - & - \\
\hline & $3 L$ & 7 & 14 & 10 & - & - & - \\
\hline & $3 M$ & 6 & 17 & 6 & - & - & - \\
\hline & $3 P$ & - & - & 1 & - & - & - \\
\hline & Total & 15 & 36 & 17 & - & - & - \\
\hline \multirow[t]{5}{*}{ S. marinus } & $2 \mathrm{~J}$ & 1 & 18 & 5 & 1 & - & - \\
\hline & $3 K$ & 1 & 5 & 1 & - & - & - \\
\hline & $3 \mathrm{~L}$ & 1 & 1 & 1 & - & - & - \\
\hline & $3 P$ & 2 & 10 & 1 & - & - & - \\
\hline & Total & 5 & 34 & 8 & 1 & - & - \\
\hline
\end{tabular}


the work of Templeman and Sandeman (1959) for 43 mentella-type redfish (now called $S$. fasciatus) and from the counting of melanophores in $170 \mathrm{~S}$. mentella larvae and $62 \mathrm{~S}$. marinus larvae from the more recent samples. The average number of melanophores per larva was 1.11 for S. mentella and 1.05 for S. marinus. The latter compares with an average of 1.07 in $1062 \mathrm{~S}$. marinus larvae (with melanophores) examined by Templeman and Sandeman (1959). For S. fasciatus, on the same basis, the average number of melanophores in 5,098 larvae was 1.89 . The melanophores were so much more distinct when contracted that the average increased to 2.11 in $S$. fasciatus larvae noted as possessing contracted melanophores (Templeman and Sandeman, 1959).

\section{Larval development and possession of subcaudal melanophores}

In female redfish, after the eggs are liberated in the lumen of the ovary and fertilized, larval development proceeds to hatching. The yolk sac, which is rather large after hatching, declines gradually as the larva grows and is very small upon extrusion. Although the objective was to obtain larvae as close as possible to the extrusion stage, it was sometimes necessary to collect larvae in earlier stages of development if samples were to be obtained at all. Only hatched larvae were examined, and it was observed that the larvae were generally better developed and the yolk sac smaller in samples with progressively higher percentages of hatched larvae. Making allowance for the small numbers of larvae grouped in certain percentage-hatched categories (Table 3 ), there is no indication that the number of larvae with subcaudal melanophores varied during larval development from hatching to extrusion in $S$. fasciatus and $S$. marinus, and the same is likely to be the case for S. mentella although there were no samples in which less than $70 \%$ were hatched.

\section{Distribution of female parents by depth and area}

The Hawke Channel-Hamilton Bank (Div. 2J) and the more northerly (Div. 2H) larval collections from mentella-type redfish in May to August at 187-375 and 457-468 $\mathrm{m}$ were all from late spawning $S$. fasciatus (Table 4). Also, 24 S. marinus were sampled at 457-468 $\mathrm{m}$ in June. However, in April at $457 \mathrm{~m}$ on Hamilton Bank, the only late stage larvae found were from $7 \mathrm{~S}$. mentella and one $S$. marinus. In the area south of Hawke Channel and on Funk Island Bank (Div. 3K), all of the larvae of mentella-type redfish from 214 to $232 \mathrm{~m}$ in April and May belonged to $S$. fasciatus females. Larvae from $S$. marinus females were also sampled in this area. Along the northeast slope of the Grand Bank (Div. 3L), larvae from $S$. fasciatus and $S$. marinus females were obtained in March at 271-371 $\mathrm{m}$. At greater depths in this area $(433-521 \mathrm{~m})$, the larval collections indicated a mixture of $S$. fasciatus and $S$. mentella, the former being more prevalent at 433-457 $\mathrm{m}$ and the latter at $501-521 \mathrm{~m}$. In the Flemish Cap area

TABLE 3. Percentage distribution of female parents in relation to the numbers of larvae with subcaudal melanophores, for parents with larvae in 3 stages of hatching.

\begin{tabular}{|c|c|c|c|c|c|c|c|c|}
\hline \multirow{3}{*}{$\begin{array}{l}\text { No. of } \\
\text { larvae }\end{array}$} & \multicolumn{8}{|c|}{ Distribution of females by percent-hatched categories } \\
\hline & \multicolumn{3}{|c|}{ S. fasciatus } & \multicolumn{2}{|c|}{ S. mentella } & \multicolumn{3}{|c|}{ S. marinus } \\
\hline & $5-50$ & $60-95$ & 100 & $70-95$ & 100 & $15-50$ & $60-95$ & 100 \\
\hline 0 & - & - & - & 27 & 22 & 8 & 17 & 8 \\
\hline 1 & - & - & - & 32 & 26 & 17 & 17 & 8 \\
\hline 2 & - & - & - & 14 & 17 & 25 & 8 & 13 \\
\hline 3 & - & - & - & 9 & 15 & 25 & - & 8 \\
\hline 4 & - & - & - & 9 & 4 & 8 & 8 & 21 \\
\hline 5 & - & - & - & - & - & - & 8 & 8 \\
\hline 6 & - & - & - & 5 & 7 & 8 & 17 & 13 \\
\hline 7 & - & - & - & - & 4 & - & 17 & - \\
\hline 8 & - & - & - & - & 2 & - & 8 & 4 \\
\hline 9 & - & - & - & - & - & - & - & - \\
\hline 10 & - & - & - & - & - & - & - & 4 \\
\hline 11 & - & - & - & 5 & 2 & - & - & - \\
\hline 12 & - & - & - & - & - & 8 & - & 8 \\
\hline 13 & - & - & 1 & - & - & - & - & 4 \\
\hline 14 & - & - & 1 & - & - & - & - & - \\
\hline 15 & 3 & 4 & - & - & - & - & - & - \\
\hline 16 & 3 & - & 1 & - & - & - & - & - \\
\hline 17 & - & - & 2 & - & - & - & - & - \\
\hline 18 & - & 4 & 2 & - & - & - & - & - \\
\hline 19 & 6 & 7 & 5 & - & - & - & - & - \\
\hline 20 & 88 & 85 & 88 & - & -- & - & - & - \\
\hline $\begin{array}{c}\text { No. of } \\
\text { females }\end{array}$ & 32 & 27 & 99 & 22 & 46 & 12 & 12 & 24 \\
\hline
\end{tabular}


(Div. 3M), all redfish females sampled in June from 271-373 $\mathrm{m}$ were $S$. fasciatus, whereas those sampled in March from 366-640 $\mathrm{m}$ were all $\mathrm{S}$. mentella. In Hermitage and Connaigre bays on the south coast of

TABLE 4. Numbers of redfish female parents of larval samples by area, depth, dates and species.

\begin{tabular}{cccccc}
\hline & Depth & Time of & \multicolumn{3}{c}{ Female parents of larval samples } \\
\cline { 5 - 7 } Div. & $(\mathrm{m})$ & sampling & S. fasciatus & S. mentella & S. marinus \\
\hline $2 H$ & $318-375$ & Aug & 4 & - & - \\
2J & $187-276$ & May-Jun & 10 & - & - \\
& $320-371$ & Aug & 3 & - & - \\
& 457 & Apr & - & 7 & 1 \\
& $457-468$ & Jun-Aug & 2 & - & 24 \\
3K & $214-232$ & Apr-May & 72 & - & 7 \\
3L & $271-371$ & Mar & 8 & - & 3 \\
& $433-457$ & Mar-Apr & 16 & 7 & - \\
& $501-521$ & Mar & 3 & 24 & - \\
3M & $271-373$ & Jun & 12 & - & - \\
& $366-457$ & Mar & - & 12 & - \\
& $521-640$ & Mar & - & 17 & - \\
3P & $199-232$ & May & - & - & 13 \\
& $241-256$ & Jul & 29 & 1 & - \\
\hline
\end{tabular}

Newfoundland (Div. 3P), all larval samples in May were from S. marinus, and the samples from late spawners in July were from S. fasciatus (29) and S. mentella (1).

\section{Species designation and meristic characters}

Analysis of meristic characteristics of $S$. fasciatus and S. mentella parent females, which were assigned to species on the basis of subcaudal melanophore occurrence in their larvae, indicates highly significant differences $(\underline{P}<0.001)$ between the average numbers for all 3 characters examined (Table 5), the greatest difference being in anal fin-ray number $(\mathrm{t}=9.81$, $\mathrm{df}=$ $70)$ compared with the $t$-values for vertebral number (7.53) and dorsal fin-ray number (6.55). The meristic averages for $S$. marinus were also similarly different from those for $S$. fasciatus. Most of the $S$. fasciatus specimens had 30 vertebrae and 7 anal fin-rays whereas the other 2 species had none in these categories. S. marinus tended to have fewer dorsal and anal fin-rays than $S$. mentella, the difference being significant $(P<0.001)$ in the case of the latter. Specimens with 32 vertebrae, 16 dorsal fin-rays and more than 8 anal fin-rays were lacking in S. fasciatus but present in $S$. mentella and $S$. marinus. Larger numbers of specimens would undoubtedly have produced more overlapping but the general trends

TABLE 5. Frequencies of meristic numbers for female parents of redfish species whose larvae were examined for subcaudal melanophores.

\begin{tabular}{|c|c|c|c|c|c|c|c|c|c|c|c|}
\hline \multirow{2}{*}{$\begin{array}{l}\text { Meristic } \\
\text { number }\end{array}$} & \multicolumn{4}{|c|}{ S. fasciatus } & \multicolumn{3}{|c|}{ S. mentella } & \multicolumn{4}{|c|}{ S. marinus } \\
\hline & $2 \mathrm{~J}$ & $3 K$ & $3 \mathrm{~L}$ & Total & $3 \mathrm{~L}$ & $3 M$ & Total & $2 \mathrm{~J}$ & $3 \mathrm{~L}$ & $3 P$ & Total \\
\hline \multicolumn{12}{|c|}{ Vertebrae } \\
\hline 30 & 2 & 1 & 10 & 13 & - & - & - & - & - & - & - \\
\hline 31 & - & 1 & 3 & 4 & 26 & 24 & 50 & 21 & 1 & 2 & 24 \\
\hline 32 & - & - & - & - & 1 & 4 & 5 & 2 & 2 & - & \\
\hline No. & & & & 17 & & & 55 & & & & 28 \\
\hline Mean & & & & 30.24 & & & 31.09 & & & & 31.14 \\
\hline S.E. & & & & 0.106 & & & 0.039 & & & & 0.067 \\
\hline
\end{tabular}

\begin{tabular}{lrrrrrrrrrrrrr}
\multicolumn{8}{c}{ Dorsal fin-rays } \\
13 & 1 & - & 7 & 8 & - & 2 & 2 & - & - & - & - \\
14 & 1 & - & 5 & 6 & 8 & 9 & 17 & 11 & 1 & 2 & 14 \\
15 & - & - & 1 & 1 & 14 & 15 & 29 & 8 & 2 & - & 10 \\
16 & - & - & - & - & 6 & 3 & 9 & 4 & - & - & 4 \\
& & & & 15 & & & 57 & & & 28 \\
No. & & & & 13.53 & & & 14.79 & & & 14.64 \\
Mean & & & & 0.165 & & & 0.099 & & & 0.138 \\
S.E. & & & & & & & &
\end{tabular}

\begin{tabular}{|c|c|c|c|c|c|c|c|c|c|c|c|}
\hline \multicolumn{12}{|c|}{ Anal fin-rays } \\
\hline 7 & 2 & - & 8 & 10 & - & - & - & - & - & - & - \\
\hline 8 & - & - & 5 & 5 & 7 & 10 & 17 & 15 & 2 & 2 & 19 \\
\hline 9 & - & - & - & - & 15 & 17 & 32 & 7 & 1 & - & 8 \\
\hline 10 & - & - & - & - & 5 & 2 & 7 & - & - & - & - \\
\hline 11 & - & - & - & - & 1 & - & 1 & - & - & - & - \\
\hline No. & & & & 15 & & & 57 & & & & 27 \\
\hline Mean & & & & 7.33 & & & 8.86 & & & & 8.30 \\
\hline S.E. & & & & 0.126 & & & 0.092 & & & & 0.089 \\
\hline
\end{tabular}


appear to be clearly shown.

When the meristic numbers were combined (Table 6), the least overlapping of S. fasciatus and the other

TABLE 6. Frequencies of combinations of meristic numbers for female parents of redfish species whose larvae were examined for subcaudal melanophores.

\begin{tabular}{lccc}
\hline \hline $\begin{array}{l}\text { Meristic } \\
\text { number }\end{array}$ & $S$. & $S$. & $s$. \\
& fasciatus & mentella & marinus \\
\hline
\end{tabular}

Dorsal + anal fin-rays

\begin{tabular}{lrrr}
20 & 6 & - & - \\
21 & 6 & 1 & - \\
22 & 2 & 4 & 11 \\
23 & 1 & 20 & 9 \\
24 & - & 22 & 5 \\
25 & - & 7 & 3 \\
26 & - & 2 & - \\
No. & 15 & 56 & 28 \\
Mean & 20.87 & 23.64 & 23.00 \\
S.E. & 0.236 & 0.131 & 0.192 \\
\hline
\end{tabular}

Vertebrae + anal tin-rays

$\begin{array}{lrrr}37 & 10 & - & - \\ 38 & 2 & - & - \\ 39 & 3 & 14 & 17 \\ 40 & - & 29 & 8 \\ 41 & - & 10 & 2 \\ 42 & - & 1 & - \\ & & & 27 \\ \text { No. } & 15 & 39.96 & 39.44 \\ \text { Mean } & 37.53 & 0.099 & 0.123 \\ \text { S.E. } & 0.215 & & \end{array}$

\begin{tabular}{lrrr}
50 & 6 & - & - \\
51 & 5 & - & - \\
52 & 2 & 1 & - \\
53 & 1 & 4 & 11 \\
54 & 1 & 18 & 7 \\
55 & - & 19 & 5 \\
56 & - & 10 & 3 \\
57 & - & 2 & 1 \\
No. & 15 & 54 & 27 \\
Mean & 51.07 & 54.72 & 54.11 \\
S.E. & 0.316 & 0.142 & 0.229 \\
\hline
\end{tabular}

species occurred for the combinations of vertebrae and anal fin-rays and of all 3 meristic characters. Statistically the differences for the 3 combinations are even more significant and $t-v a l u e s$ of 10.25-10.55 ( $\mathrm{df}=$ 67) from comparing $S$. fasciatus and $S$. mentella and of $7.01-7.79(\mathrm{df}=40)$ from comparing $S$. fasciatus and $S$. marinus.

In view of the reported lack of subcaudal melanophores in S. mentella and the relative lack in $S$. marinus from the east and central North Atlantic, as discussed later, the larger numbers of larvae of these species from the North American Shelf possessing these melanophores indicate the possibility of interbreeding, at least between $S$. fasciatus and the other species. If interbreeding occurs, it could be expected that the larval groups with the highest number of melanophores (19-20) in S. fasciatus and those with the lowest number of melanophores (0-1) in $S$. mentella and $S$. marinus would show the least indication of interbreeding. In Table 7, these ideas are examined by applying available meristic data of the female parents to the range of larval groups possessing subcaudal melanophores. It would be expected that any lack of subcaudal melanophores in larvae of female $S$. fasciatus came from the heredity of the female or male parents of this species or, if interbreeding occurs, from a S. mentella or S. marinus male. Similarly for $S$. mentella or $S$. marinus females possessing larvae with subcaudal melanophores, the presence of melanophores could have come from the heredity of the female and males of the same species or from interbreeding with a male of another redfish species. Of these possibilities, only the effects of the heredity of the female parent can be tested by comparing its meristic characters with the proportion of its larvae with subcaudal melanophores. Few comparative meristic and melanophore data are available for $S$. fasciatus, but there is no indication (Table 7) that the S. marinus and S. mentella female parents of the larval groups (3-6 and 7-12) with more subcaudal melanophores had meristic numbers closer to those of $S$. fasciatus than the larval groups (0-2) with relatively few melanophores.

TABLE 7. Relation of meristic numbers in female parents of redfish species to numbers of larvae with subcaudal melanophores

\begin{tabular}{|c|c|c|c|c|c|c|c|c|c|c|c|c|c|c|c|c|c|c|c|c|c|}
\hline \multirow[b]{2}{*}{ Species } & \multirow{2}{*}{$\begin{array}{l}\text { No. of } \\
\text { larvae }^{a}\end{array}$} & \multicolumn{3}{|c|}{ Vertebrae } & \multicolumn{4}{|c|}{ Dorsal fin-rays } & \multicolumn{5}{|c|}{ Anal fin-rays } & \multicolumn{8}{|c|}{ Sum of 3 meristic characters } \\
\hline & & 30 & 31 & 32 & 13 & 14 & 15 & 16 & 7 & 8 & 9 & 10 & 11 & 50 & 51 & 52 & 53 & 54 & 55 & 56 & 57 \\
\hline S. fasciatus & $19-20$ & 13 & 4 & - & 8 & 6 & 1 & - & 10 & 5 & 一 & - & - & 6 & 5 & 2 & 1 & 1 & - & - & - \\
\hline \multirow[t]{3}{*}{ S. mentella } & $7-11$ & - & 3 & 1 & - & 1 & 1 & 2 & - & - & 4 & - & - & - & - & - & - & 1 & - & 3 & - \\
\hline & $3-6$ & - & 16 & - & 1 & 6 & 6 & 2 & - & 3 & 10 & 2 & - & - & - & - & 1 & 7 & 5 & 2 & - \\
\hline & $0-2$ & - & 32 & 3 & 1 & 10 & 22 & 5 & - & 14 & 18 & 5 & 1 & - & - & 1 & 3 & 9 & 15 & 5 & 2 \\
\hline \multirow[t]{3}{*}{ S. marinus } & $7-12$ & - & 5 & - & - & 3 & 1 & 1 & - & 3 & 2 & - & - & - & - & - & 3 & - & 1 & 1 & - \\
\hline & $3-6$ & - & 15 & 1 & - & 9 & 6 & 2 & - & 12 & 4 & - & - & - & - & - & 7 & 4 & 4 & 1 & - \\
\hline & $0-2$ & - & 4 & 2 & - & 2 & 4 & 1 & - & 4 & 3 & - & - & - & - & - & 1 & 3 & - & 1 & 1 \\
\hline
\end{tabular}

${ }^{a}$ Number of larvae with subcaudal melanophores per sample of 20 larvae. 


\section{Relation of stage of larval development and meristic characters to species and depth distribution}

In view of the apparent differences in meristics (Tables 5 and 6 ) and in depth distribution (Table 4) of $S$. fasciatus and $S$. mentella, which were assigned to species on the basis of differences in the incidence of subcaudal melanophores in their larvae, additional data on meristics and stage of larval development in mentella-type female redfish taken at Flemish Cap and Northeast Grand Bank in March 1961 were examined for further evidence of differences in depth distribution and spawning of the two species.

At Flemish Cap (Div. 3M) in late March (Table 8), the eggs and larvae of mentella-type females taken at depths of 274-320 m were in early stages of development and the meristics of the parents were typical of those found in S. fasciatus. At 357-439 m, for the pre-larval and early larval stages, the meristics of the females were again typical of $S$. fasciatus, whereas for those with hatched larvae the meristics were typical of $S$. mentella. At greater depths (457-640 m), almost all mature females had some hatched larvae and a few were spent, and their meristics were typical of $S$. mentella.

For Northeast Grand Bank (Div. 3L) in late March (Table 8), the meristics of mature females at 262-320 and 364-371 m were all typical of $S$. fasciatus and only a few of the specimens had larvae more than $40 \%$ hatched. At 433-521 m, the meristics of females in the first two categories (early larvae to $1-40 \%$ hatched larvae) were mainly typical of $S$. fasciatus, the more numerous fish with $50-100 \%$ hatched larvae indicate a mixture of S. fasciatus and S. mentella, but mainly the latter, and those in the Spent $P$ condition were typical of S. mentella.

Similar data for $S$. marinus females from Flemish Cap in late March (Table 8) indicate that most contained less than $20 \%$ hatched larvae and that the meristics were similar to those of $S$. marinus from other areas (Tables 5 and 6 ), for which the larvae were examined. The great range in stage of egg and larval development, and the corresponding differences in meristics of mentella-type redfish which included two species, were not evident in S. marinus. The relatively early stage of larval development in most samples of $S$. marinus indicates later spawning (larval extrusion) for S. marinus than for S. mentella.

\section{Discussion}

\section{Presence of subcaudal melanophores in redfish larvae}

Templeman and Sandeman (1959) found that unextruded larvae of the sharp-beaked mentella-type redfish of the Newfoundland area typically had 1-4 subcaudal melanophores obliquely placed between a pair of neuromasts. In contrast, a much smaller

TABLE 8. Frequencies of meristic numbers in relation to stage of egg and larval development for female redfish from Flemish Cap (Div. $3 M$ ) and Northeast Grand Bank (Div. 3L) in late March 1961. [Spent $P=$ spent in present year (year of examination); Spent $L=$ spent in previous year.]

\begin{tabular}{|c|c|c|c|c|c|c|c|c|c|c|c|c|c|c|c|c|c|c|c|c|c|c|c|c|c|c|c|c|}
\hline \multirow[b]{2}{*}{ Div. } & \multirow{2}{*}{$\begin{array}{l}\text { Depth } \\
\text { (m) }\end{array}$} & \multirow{2}{*}{$\begin{array}{l}\text { Stage of larval } \\
\text { development }\end{array}$} & \multirow{2}{*}{$\begin{array}{l}\text { No. of } \\
\text { temales }\end{array}$} & \multicolumn{3}{|c|}{ Vertebrae } & \multicolumn{6}{|c|}{ Dorsal fin-rays } & \multicolumn{6}{|c|}{ Anal fin-rays } & \multicolumn{10}{|c|}{ Vertebrae + dorsal + anal fin-rays } \\
\hline & & & & 30 & 31 & 32 & 12 & 13 & 14 & 15 & 16 & 17 & 6 & 7 & 8 & 9 & 10 & 11 & 49 & 50 & 51 & 52 & 53 & 54 & 55 & 56 & 57 & 58 \\
\hline \multicolumn{29}{|c|}{ Mentella-type redish } \\
\hline \multirow[t]{9}{*}{$3 M$} & $274-320$ & Prelarval - $0 \%$ hatched & 7 & 7 & - & - & - & 4 & 2 & 1 & - & - & - & 4 & 3 & $\cdots$ & $\ldots$ & - & - & 2 & 4 & - & 1 & - & - & - & - & - \\
\hline & & Spent $P$ & 1 & 1 & - & - & - & 1 & - & - & - & - & - & - & - & 1 & - & - & - & - & - & 1 & - & - & - & - & - & - \\
\hline & $357-439$ & Prelarval - $0 \%$ hatched & 11 & 9 & 1 & - & - & 3 & 8 & - & - & - & - & 7 & 4 & - & - & - & - & 2 & 5 & 3 & - & - & - & - & - & - \\
\hline & & $1-5 \%$ hatched & 1 & - & - & 1 & - & - & 1 & - & - & - & - & - & - & 1 & - & - & - & - & - & - & $\rightarrow$ & - & 1 & - & - & - \\
\hline & & $70-100 \%$ hatched & 5 & - & 4 & - & - & - & 2 & 3 & - & - & - & - & 3 & 2 & - & - & - & - & - & - & - & 4 & - & - & - & - \\
\hline & $457-640$ & Prelarvai $-0 \%$ hatched & 3 & - & 2 & 1 & - & - & - & 3 & - & - & - & - & 1 & 2 & - & - & - & - & - & - & - & 1 & 1 & 1 & - & $一$ \\
\hline & & $1-40 \%$ natched & 50 & - & 33 & 14 & - & - & 19 & 24 & 6 & 1 & - & 1 & 10 & 35 & 4 & - & - & - & - & - & 3 & 12 & 19 & 10 & 2 & 1 \\
\hline & & $50-100 \%$ hatched & 56 & - & 44 & 12 & - & 2 & 14 & 26 & 12 & 1 & - & - & 15 & 36 & 5 & - & - & - & $\ldots$ & 1 & 3 & 15 & 20 & 12 & 3 & 1 \\
\hline & & Spent $P$ & 4 & 1 & 2 & 1 & - & - & 1 & 3 & - & - & - & - & 3 & 1 & - & - & - & - & - & - & 1 & 2 & 1 & - & - & - \\
\hline \multirow[t]{11}{*}{ 3L } & $262-320$ & Prelarvai - $0 \%$ hatched & 3 & 3 & - & - & - & - & 2 & 1 & - & - & - & 2 & 1 & - & - & - & - & - & 2 & - & 1 & - & - & - & - & - \\
\hline & & $1-40 \%$ natched & 30 & 17 & 12 & - & 2 & 14 & 14 & - & - & - & - & 10 & 20 & - & - & - & 1 & 6 & 7 & 9 & 6 & - & - & - & - & - \\
\hline & & $70-100 \%$ hatched & 4 & 3 & 1 & - & - & 2 & 2 & - & - & - & - & 3 & 1 & - & - & - & - & 1 & 2 & 1 & - & - & - & - & - & - \\
\hline & $364-371$ & Prelarval - $0 \%$ hatched & 10 & 6 & 3 & - & - & 4 & 6 & - & - & - & - & 9 & - & - & - & - & - & 4 & 2 & 2 & 1 & - & - & - & - & - \\
\hline & & $1-30 \%$ hatched & 19 & 18 & 1 & - & 1 & 7 & 11 & - & - & - & 1 & 13 & 5 & - & - & - & 1 & 5 & 10 & 3 & - & - & - & - & - & - \\
\hline & & $70-100 \%$ hatched & 8 & 6 & 2 & - & - & 3 & 5 & - & -. & - & - & 4 & 3 & 1 & - & - & - & 2 & 2 & 2 & 2 & - & - & - & - & - \\
\hline & & Spent $P$ & 1 & 1 & - & - & 1 & - & - & - & - & - & - & - & - & - & - & - & - & 1 & - & - & - & - & - & - & - & - \\
\hline & $433-521$ & Prelarval - $0 \%$ hatched & 3 & 2 & 1 & - & - & 2 & - & 1 & - & - & - & 2 & 1 & - & - & - & - & 2 & - & - & - & 1 & - & - & - & - \\
\hline & & $1-40 \%$ & 17 & 14 & 3 & - & -- & 9 & 6 & 2 & - & - & - & 12 & 4 & 1 & - & - & - & 8 & 4 & 2 & 1 & 2 & - & - & - & - \\
\hline & & $50-100 \%$ hatched & 49 & 8 & 35 & 2 & - & 5 & 15 & 22 & 7 & - & - & 6 & 15 & 21 & 6 & 1 & - & 5 & 1 & 2 & 2 & 12 & 13 & 8 & 2 & - \\
\hline & & Spent $P$ & 9 & - & 7 & 2 & - & - & 4 & 4 & 1 & - & - & - & 2 & 6 & 1 & - & - & - & - & - & 1 & 3 & 3 & 1 & 1 & - \\
\hline \multicolumn{29}{|c|}{ S. marinus } \\
\hline \multirow[t]{4}{*}{$3 M$} & $274-366$ & Prelarval - $0 \%$ hatched & 6 & - & 4 & 2 & - & - & 1 & 3 & 2 & - & - & - & 4 & 2 & - & - & - & - & - & - & - & 2 & 3 & 1 & - & - \\
\hline & & $1-20 \%$ hatched & 24 & - & 21 & 2 & - & - & 5 & 13 & 6 & - & - & - & 13 & 11 & - & - & - & - & - & - & 3 & 9 & 7 & 4 & - & - \\
\hline & & Spent $P$ & 2 & - & 1 & 1 & - & - & - & - & 2 & - & - & 一 & 1 & 1 & - & - & - & - & - & - & - & - & 1 & $\ldots$ & 1 & - \\
\hline & & Spent L & 1 & - & 1 & - & - & - & - & 1 & - & - & - & - & 1 & - & - & - & - & - & - & - & - & 1 & - & - & - & -. \\
\hline
\end{tabular}


proportion of the larvae of $S$. marinus possessed these melanophores, usually only one when present. In this paper, all except one of the mentella-type specimens of Templeman and Sandeman (1959) are recognized as S. fasciatus.

Kotthaus (MS 1961) did not find subcaudal melanophores in unextruded larvae of $S$. marinus and S. mentella taken off Southwest Iceland. Raitt (1964), in redfish from the south coast of Iceland, found no larvae with subcaudal melanophores in a S. mentella, 1 larva in a $S$. marinus and 12 larvae in a second $S$. marinus, in samples of 100 larvae from each fish. Henderson (1964), Henderson and Jones (1964), and Jones (1968) found that unextruded larvae of oceanic S. mentella caught at Ocean Weather Station A, southwest of Iceland $\left(62^{\circ} \mathrm{N}, 33^{\circ} \mathrm{W}\right)$, did not possess subcaudal melanophores. Templeman (1967) obtained similar results from the examination of larvae of 4 oceanic $S$. mentella taken in the Labrador Sea in July. However, because of the late date, only 9 larvae suitable for examination were found. Further examination of unextruded larvae from this area, preferably collected earlier in the year before spawning, is desirable.

Corlett (1961b) found that none of 116 redfish larvae, mainly 7-9 mm long, taken in April-May at Ocean Weather Station A had subcaudal melanophores. Einarsson (1960) found that Sebastes larvae (except $S$. viviparus) from Iceland waters and the Irminger Sea did not possess subcaudal melanophores. Magnússon et al. (1965) examined large numbers of redfish larvae from the Irminger Sea and found none with subcaudal melanophores except a few S. viviparus. Bainbridge and Cooper (1971), and referring also to Henderson (1965a, 1965b, 1968), said that, of several thousand redfish larvae examined over a period of more than 10 years from the oceanic area from southwest Iceland and south Greenalnd to north of Flemish Cap, none possessed subcaudal melanophores. Since the adults in the oceanic area are $S$. mentella, these larvae were the offspring of that species. However, a few of the larvae taken in the vicinity of Flemish Cap and most of the larvae taken in other areas off the North American coast from Labrador to the Gulf of Maine possessed subcaudal melanophores.

\section{Identity of S. fasciatus and S. mentella}

In the data presented in this paper, the sharpbeaked mentella-type redfish were well separated into two groups, $S$. fasciatus, in which all or nearly all of the unextruded larvae typically possessed subcaudal melanophores, and $S$. mentella, in which the unextruded larvae only occasionally possessed these melanophores. Moreover, the S. mentella had smaller melanophores with less pigment, spawned earlier, were found in deeper water and had higher meristic numbers than $S$. fasciatus from the same area.

The presence of one or more subcaudal melanophores in some of the S. mentella larvae from the Labrador-Newfoundland area makes them different in this respect from the basic $S$. mentella stocks off Iceland and in the northeastern and oceanic parts of the North Atlantic, whose larvae were reported to have no subcaudal melanophores. It is possible that the presence of melanophores in some of the $S$. mentella larvae from the North American shelf and slope areas indicates interbreeding, presumably with S. fasciatus.

In view of the discrepancy in reports of the presence or absence of subcaudal melanophores in larvae of S. marinus by Kotthaus (MS 1961) and Raitt (1964), and the unknown numbers of fish examined by the former and the small number examined by the latter, there is still some doubt regarding the relative proportions of $S$. marinus larvae with subcaudal melanophores in the various regions of the North Atlantic. However, from the data presented by Templeman and Sandeman (1959) and also in this paper, indicating the presence of subcaudal melanophores in up to $50 \%$ of the unextruded larvae in some samples from the North American Shelf areas, it seems likely that $S$. marinus larvae from these areas possess more subcaudal melanophores than larvae from other North Atlantic regions. If this is so, interbreeding presumably occurs with S. fasciatus.

\section{Meristics}

Allowing for the small numbers of specimens examined, the meristic frequencies (vertebrae, dorsal fin-rays and anal fin-rays) for $S$. fasciatus and $S$. mentella (Table 5), which were separated in samples of mentella-type redfish by subcaudal melanophore differences in unextruded larvae, are generally similar to those of Barsukov and Zakharov (1972). However, these authors did not indicate how their mentella-type redfish were assigned to $S$. fasciatus and $S$. mentella preliminary to their study of meristic characters. Additionally, Tåning's vertebral numbers for $S$. fasciatus, listed in Appendix II of Kelly et al. (1961), are similar to those for $S$. fasciatus in this paper (Table 5), and the anal fin-ray counts are similar in pattern. The region of origin and methods of selection of Tåning's sample of $S$. fasciatus were not stated, but he regarded all North American Shelf sharp-beaked redfish as $S$. fasciatus.

The meristic frequencies for S. mentella (Table 5) are similar to the unpublished data for oceanic $S$. mentella (Templeman, 1967) from the Labrador Sea (in $15 \mathrm{~S}$. mentella: vertebral numbers, 30(1), 31(11), 32(1); dorsal fin-ray numbers, $13(1), 14(9), 15(5)$; and anal 
fin-ray numbers, $8(7), 9(8))$. The meristic ranges are similar to those of $S$. mentella reported by Travin (1951). The vertebral numbers for S. mentella (Table 5) are also similar to those for $S$. mentella from Ocean Weather Station A in the Irminger Sea (Jones, 1969). However, the average number of vertebrae in Taning's sample of S. mentella (Kelly et al., 1961, App. II) was lower than that for his S. fasciatus and almost as low as that for his S. viviparus. It was also 0.77 vertebrae lower than that of his S. marinus, whereas it should have been approximately the same or only slightly lower or higher. The locality of capture of these S. mentella was not stated but they were probably from the Iceland area. A possible explanation for the low vertebral average in Taning's $S$. mentella is that the urostylar half-vertebra was not included in the counts for that species but was apparently included for the other 3 species.

\section{Egg and larval development in relation to depth and species}

Inferences on distribution by depth of the two types of sharp-beaked mentella-type redfish in March at Flemish Cap and Northeast Grand Bank (Table 8) indicate that $S$. fasciatus occurred at shallower depths and had relatively higher proportions of eggs and larvae in early developmental stages than S. mentella. Therefore, since $S$. mentella tend to mature and spawn earlier in the year than S. fasciatus, all (except one) of the mentella-type redfish taken in June and early July 1958 (Table 1) and examined by Templeman and Sandeman (1959) were $S$. fasciatus. This includes the 12 S. fasciatus from Flemish Cap in late June 1958, whereas all specimens collected from this area in March 1961 for examination of larvae were S. mentella.

\section{Implications for management}

Although no mentella-type redfish larvae were available for examination from the area extending from Baffin Island southward to the Labrador Shelf (about $57 \%)$, it is most likely that all sharp-beaked redfish in the area are S. mentella. Some S. fasciatus occurred on the Labrador shelf from about $55^{\circ} 30^{\prime} \mathrm{N}$ southward, but they were not plentiful relative to $S$. mentella, except from about $53^{\circ} 40^{\prime} \mathrm{N}$ southward. In the whole area from Labrador to Flemish Cap the sharp-beaked redfish deeper than about $400 \mathrm{~m}$ were $S$. mentella, there being occasional exceptions with area and season (unpublished meristic data, St. John's Station). In March 1961 at Northeast Grand Bank (Div. 3L), all sharp-beaked redfish from 262 to $371 \mathrm{~m}$ were $S$. fasciatus, there was a mixture of $S$. fasciatus and $S$. mentella at $433-457 \mathrm{~m}$, and nearly all were $S$. mentella at $501-521 \mathrm{~m}$. These observations agree generally with those of Barsukov and Zakharov (1972). The oceanic redfish of the Labrador Sea (Templeman, 1967) had the meristic characteristics of S. mentella.

Almost all of the female $S$. mentella off Baffin Island and northern Labrador and in depths greater than $550 \mathrm{~m}$ from Labrador Shelf and Funk Island Bank were immature, even though some were $46-48 \mathrm{~cm}$ in length, close to the maximum size $(49-53 \mathrm{~cm})$ for $S$. mentella females of the area, the few mature females at these depths being more usually present in spring than in late summer (Templeman, 1955, 1961a, 1964); Savvatimsky and Sidorenko, 1966; Sandeman, 1969; Zakharov and Chekhova, 1972; Chekhova, 1972). This scarcity of mature females of $S$. mentella, off Baffin Island and northern Labrador and in deep water southward to Div. 3K, greatly reduces the spawning potential of the species in this area. Savvatimsky and Sidorenko (1966) raise the possibility that these immature deepwater redfish are hybrids, but this is very unlikely as their meristics and morphometrics indicate that they are distinctly $S$. mentella. The main explanation for their immaturity is likely to be the depth and consequently the light and temperature relationships throughout their life history, because immaturity of redfish at large sizes from deep water is not evident at Flemish Cap where the three species are present and where temperatures at redfish depths are more uniformly above $3^{\circ} \mathrm{C}$ than in more northern areas.

The presence, in an area such as Flemish Cap and other parts of the North American Shelf, of two or three redfish species, of which the two sharp-beaked mente/la-type species are similar in appearance and usually more numerous, offers obvious problems for management, as these three species are now treated as a single group for management purposes. However, these species tend to live at different depths, spawn at different times, differ in spawning sizes and presumably differ in growth rates, with consequent differences in the nursery areas inhabited by the juveniles. The larvae are affected differently by currents, temperature conditions and plankton blooms, with consequent effects on larval growth and mortality. The redfish populations are also undoubtedly affected differently by trawling practices. Redfish may live for 40-50 years or more, and good year-classes are usually not frequent, a large one being known to support a fishery for many years. Also, the different species may have good year-classes in different years. S. marinus is often present but usually not plentiful in Subareas 2 and 3 , is very uncommon in the northern part of Subarea 4 , and is not present (except for rare specimens) in the southern part of Subarea 4 and in Subarea 5. Thus, the two species likely to be numerous enough to have a significant effect on the redfish fisheries of the North American Shelf are $S$. fasciatus and $S$. mentella. 
An example of differences in the vertebral frequencies of two size groups of mentella-type redfish in Hermitage Bay during 1947-54 was noted by Templeman and Pitt (1961), the larger fish having somewhat higher vertebral counts on the average than the smaller sizes. At the time, for both Hermitage Bay and the Gulf of St. Lawrence, these authors attributed the variation in vertebral numbers to temperature differences during larval development in a single species of sharp-beaked redfish which they considered to be $S$. mentella. Now, in view of more knowledge of redfish species and their meristic characteristics (Barsukov, 1968; Barsukov and Zakharov, 1972; this paper and unpublished records of the Newfoundland Biological Station), it is more likely that the group of larger redfish with predominantly high vertebral numbers (31-32) were $S$. mentella, and that most of the smaller group with predominantly low vertebral numbers $(30)$ were $S$. fasciatus.

If one of these species, in an area where both are important, is overfished to the point where its reproductive ability is severely reduced, the frequency of good year-classes will depend largely on the other species and the overall production of year-classes may then be decreased. Even if regarded as one species, redfish stocks are difficult to assess and manage because of difficulties in ageing, differences in ageing techniques among scientists of different countries, the slow growth rate and the considerable number of years that redfish can be fished before they mature. Their schooling propensities render them easy to catch, with a consequent tendency for the stocks to be overfished. The use of large mid-water trawls in recent years has removed the protection provided by the semi-pelagic nature of these fish and has thus intensified overfishing.

Management of the redfish stocks is further complicated by the problems of the separation of the commercial catches by species, the prevalence of a high proportion of large immature redfish in the north, and possibility of interbreeding between species. If interbreeding occurs, there are the problems of recognizing the hybrids and determining whether they are fertile. Since redfish tend to go deeper as they become larger and the large immatures in the north are close to maximum size, these immature redfish from Funk Island Bank northward at depths greater than 550 $m$ can probably be fished without affecting significantly the production of young redfish. However, Sandeman (1969) noted, for mentella-type redfish of the Hamilton Bank area (Div. 2J), that these immature females at $550 \mathrm{~m}$ were faster-growing, reaching a greater maximum size but lower maximum age ( 29 years), than females at $370-460 \mathrm{~m}$, some of which were more than 40 years old. If some of the immature females at the greatest depths become mature, they do so at such a great age as to be very few in number under heavy fishing pressure.

\section{Acknowledgements}

I am grateful to W. D. McKone for providing copies of St. John's Station redfish data, to E. J. Sandeman for the privilege of re-using redfish larval data previously gathered with the author and to S. H. Lee and Mrs Joan V. Arklie who contributed to assembling the data.

\section{References}

BAINBRIDGE, V., and G. A. COOPER. 1971. Populations of Sebastes larvae in the North Atlantic. ICNAF Res. Bull., No. 8: 27-35.

BARSUKOV, V. V. 1968. The systematic relationship of redfishes of the genus Sebastes of the Northwest Atlantic Ocean. Doklady Akad. Nauk SSSR, 183(2): 479-482. (Transl. from Russian in Doklady Bioi. Sci., 183 (1-6), Nov. - Dec. 1968, p. 734-737).

1972. Systematics of the Atlantic redfishes. Trudy PINRO, 28 128-142. (Fish. Res. Bd. Canada Transl. Ser. No. 2531, 1973).

BARSUKOV, V. V., and G. P. ZAKHAROV. 1972. Morphological and biological characteristics of the American redfish. Trudy PINRO, 28: 143-173. (Fish. Res. Bd. Canada Transl. Ser. No. 2488, 1973).

BIESTER, E., W. RANKE, J. VOSS, and W. GRAEF. MS 1962. Research Report of the German Democratic Republic, 1961. ICNAF Res. Doc., No. 60, Serial No. 1003.

CHEKHOVA, V. A. 1972. Vertical distribution of beaked redfish (Sebastes mentella Travin) on the Flemish Cap Bank. Trudy PINRO, 28: 199-209. (Fish. Res. Bd. Canada Transl., Ser. No. 2504 , 1973).

CORLETT, J. 1961a. Distribution of redfish larvae in the western Barents Sea. ICNAF Spec. Publ., No. 3: 188-193.

$1961 b$. Redfish larvae from Ocean Weather Station "A" in $62^{\circ} \mathrm{N}, 33^{\circ} \mathrm{W}$. Ibid., p. 194.

EINARSSON, H. 1960. The fry of Sebastes in Icelandic waters and adjacent seas. Rit Fiskideildar, 2(7): 1-67.

HALLACHER, L. E. 1974. The comparative morphology of extrinsic gasbladder musculature in the Scorpionfish genus Sebastes (Pisces: Scorpaenidae). Proc. Cal. Acad. Sci., Ser. 4, 40(3):59-86.

HANSEN, V. K., and K. P. ANDERSEN. 1961. Recent Danish investigations on the distribution of larvae of Sebastes marinus in the North Atlantic. ICNAF Spec. Publ., No. 3: 201-215.

HENDERSON, G. T. D. 1961. Continuous plankton records. The distribution of young Sebastes marinus (L). Bull. mar. Ecol., 5 173-193.

1964. Identity of larval redfish populations in the North Atlantic. Nature, 201: 419.

1965a. Sebastes in continuous plankton records in 1963. Ann. biol. Copenhague, 20: 85-87.

1965b. Redfish larvae in the North Atlantic. ICNAF Spec. Publ., No. 6: 309-315.

1968. Continuous plankton records during the Norwestlant surveys 1963 - Young redfish. Ibid., No. 7: (1) 157-161.

HENDERSON, G. T. D., and D. H. JONES. 1964. Adult redfish in the open ocean. ICNAF Res. Bull., No. 1: 107-109.

JONES, D. H. 1968. Angling for redfish. ICNAF Spec. Publ., No. 7(1): 225-240.

1969. Some characteristics of the pelagic redfish (Sebastes mentella Travin) from Weather Station Alfa. J. Cons., 32: 395-412.

KELLY, G. F., A. M. BARKER, and G. M. CLARKE. 1961. Racial comparisons of redfish from the western North Atlantic and the Barents Sea. ICNAF Spec. Publ., No. 3: 28-41.

KOTTHAUS, A. MS 1961.. Redfish larvae investigations in the central North Atlantic in 1961. (Preliminary report). ICES, Distant Northern Seas Committee, C.M. Doc. No. 4 
LITVINENKO, N. N. 1974. Coloration and other morphological characters distinguishing juvenile Sebastes fasciatus from juvenile S. mentella (Scorpaenidae). J. Ichthyol. 14: 591-595.

MAGNÚSSON, Ja., JU. MAGNÚSSON, and I. HALLGRIMSSON. 1965 The "Aegir" redfish larvae expedition to the Irminger Sea in May 1961. Cruise report and biological observations. Rit Fiskideildar, 4(2): $1-86$

RAITT, D. F.S. 1964. Scottish redfish larval investigations in 1962 with some observations on mid-oceanic echo-traces. J. Cons., 29: 65-72.

SANDEMAN, E. J. 1969. Age determination and growth rate of redfish, Sebastes sp., from selected areas around Newfoundland. ICNAF Res. Bull., No. 6: 79-106.

SAVVATIMSKY, P. I., and I. N. SIDORENKO. 1966. Results of investigations on deep-sea redfish. ICNAFRes. Bull., No. 3: 49-54.

STORER, D. H. 1856. A new species of fish (Sebastes fasciatus) from Provincetown, found in the harbor at that place. Proc. Boston Soc. Nat. Hist., 5: 31.

TÅNING, A. V. 1949. On the breeding places and abundance of the redfish (Sebastes) in the North Atlantic. J. Cons., 16: 85-95.

1961. (with introductory note by $E$. Bertelsen). Larval and postlarval stages of Sebastes species and Helicolenus dactylopterus. ICNAF Spec. Publ., No. 8: 234-240.

TEMPLEMAN, W. 1955. Canadian researches, 1954. Subareas 2 and 3. ICNAF Annu. Proc., 5: 19-22.

1957. Redfish exploration north of Flemish Cap. Fish. Res. Bd. Canada, Atlant. Prog. Rept., No. 67: 14-18.

1959. Redfish distribution in the North Atlantic. Bull. Fish. Res. Bd. Canada, No. 120, 173 p.

1961a. Redfish distribution off Baffin Island, northern Labrador, and in Ungava Bay in August-September 1959. Rapp. Cons. Explor. Mer, 150: 157-162.

1961b. Canadian research report, 1960. A. Subareas 2 and 3.

ICNAF Annu. Proc., 11: 23-31.

1964. Canadian research report, 1963. A. Subareas 2 and 3.

ICNAF Redbook 1964, Part II: 3-21.

1966. Canadian research report, 1965. A. Subareas 1,2 and 3. Ibid, 1966, Part II: 3-13.
1967. Adult redfish, Sebastes mentella, pelagic over oceanic depths in the Labrador Sea. J. Fish. Res. Bd. Canada, 24: 1275-1290.

1973. First records of the gymnoblastic hydroid, Ichthyocodium sarcotretis, on the copepod, Sphyrion lumpi, from redfish of the Northwest Atlantic. Ibid., 30: 1655-1660.

1976. Biological and oceanographic background of Flemish Cap as an area for research on the reasons for year-class success and failure in cod and redfish. ICNAF Res. Bull., No. 12: 91-117.

TEMPLEMAN, W., V. M. HODDER, and R. WELLS. 1978. Sexual maturity and spawning in haddock, Melanogrammus aeglefinus. of the southern Grand Bank. ICNAF Res. Bull., No. 13: 53-65.

TEMPLEMAN, W., and T. K. PITT. 1961. Vertebral numbers of redfish Sebastes marinus (L.), in the North-west Atlantic, 1947-1954. Rapp. Cons. Explor. Mer, 150: 56-89.

TEMPLEMAN, W., and E. J. SANDEMAN. 1957. Two varieties of redfish in the Newfoundland area. Fish. Res. Bd. Canada, Atlant. Prog. Rept., No. 66: 20-23.

1959. Variations in caudal pigmentation in late-stage preextrusion larvae from marinus- and mentella-type female redfish from the Newfoundland area. J. Fish. Res. Bd. Canada, 16: 763-789.

TRAVIN, V. I. 1951. A new species of sea perch in the Barents Sea (Sebastes mentella Travin, Sp. nov.) Doklady Akad. Nauk SSSR, 77: 741-744. (Transl. from Russian by C. R. Robins, 1955).

ZAKHAROV, G. P. 1962. Biology of the West Greenland Sebastes marinus. In: Soviet Fisheries Investigations in the Northwest Atlantic. VNIRO-PINRO, Moskva. (Transi, for U. S. Dep. Int. Nat Sci. Found. Washington, D. C. by Israel Prog. Sci. Transl., 1963), p. $311-323$

1964. Redfish above the ocean depths. ICNAF Res. Bull., No. 1: $39-42$

1967. On sexual maturation of Sebastes marinus $L$. of the North Atlantic. Trudy PINRO, 20: 248-266. (Fish. Res. Bd. Canada Transl. Ser., No. 1135, 1968).

ZAKHAROV, G. P., and V. A. CHEKHOVA. 1972. Distribution and biological characteristics of beaked redfish (Sebastes mentella Travin) of the Davis Strait. Trudy PINRO, 28: 184-198 (Transl. Ser. Fish. Res. Bd. Canada, No. 2474, 1973). 
